\title{
P- and S-wavefield simulations using both the first- and second-order separated wave equations through a high-order staggered grid finite-difference method
}

\author{
Chao-ying Bai $\cdot$ Xin Wang $\cdot$ Cai-xia Wang
}

Received: 28 June 2013/ Accepted: 20 August 2013/Published online: 2 November 2013

(C) The Seismological Society of China, Institute of Geophysics, China Earthquake Administration, and Springer-Verlag Berlin Heidelberg 2013

\begin{abstract}
In seismic exploration, it is common practice to separate the $\mathrm{P}$-wavefield from the $\mathrm{S}$-wavefield by the elastic wavefield decomposition technique, for imaging purposes. However, it is sometimes difficult to achieve this, especially when the velocity field is complex. A useful approach in multi-component analysis and modeling is to directly solve the elastic wave equations for the pure P- or $\mathrm{S}$-wavefields, referred as the separate elastic wave equations. In this study, we compare two kinds of such wave equations: the first-order (velocity-stress) and the secondorder (displacement-stress) separate elastic wave equations, with the first-order (velocity-stress) and the secondorder (displacement-stress) full (or mixed) elastic wave equations using a high-order staggered grid finite-difference method. Comparisons are given of wavefield snapshots, common-source gather seismic sections, and individual synthetic seismogram. The simulation tests show that equivalent results can be obtained, regardless of whether the first-order or second-order separate elastic wave equations are used for obtaining the pure P- or $\mathrm{S}$-wavefield. The stacked pure $\mathrm{P}$ - and S-wavefields are equal to the mixed wave fields calculated using the corresponding first-order or second-order full elastic wave equations. These mixed equations are computationally
\end{abstract}

C. Bai $\cdot$ X. Wang $\cdot$ C. Wang

Department of Geophysics, College of Geology Engineering and

Geomatics, Chang'an University, Xi' an 710054, China

C. Bai $(\bowtie)$

Institute of Computing Geophysics, Chang'an University,

Xi' an 710054, China

e-mail: baicy@chd.edu.cn slightly less expensive than solving the separate equations. The attraction of the separate equations is that they achieve separated P- and S-wavefields which can be used to test the efficacy of wave decomposition procedures in multi-component processing. The second-order separate elastic wave equations are a good choice because they offer information on the pure $\mathrm{P}$-wave or S-wave displacements.

Keywords Finite-difference method - Staggered grid - First-order separate elastic wave equation . Second-order separate elastic wave equation . Multiple arrival tracking

\section{Introduction}

The separation of the P- and S-wavefields in an isotropic medium is very important for characterizing the kinematic and dynamic features of seismic wave propagation and in applications to real problems, such as rock property determinations, seismic imaging (i.e., Sun et al. 2004; Yan and Xie 2012), receiver function analysis (Shang et al. 2012), and fracture characterization (Fang et al. 2012; Fang et al. 2013). Traditionally, P- and S-wavefield separation has been achieved using triaxial sensing and full vector-processing techniques, such as multi-component tau-p filtering (i.e., Greenhalgh et al. 1990) and f-k filtering (i.e., Donati and Stewart 1996); through the frequency-domain parametric equations (i.e., Leaney 1990; Cho 1991; Hendrick and Hearn 2003); and by taking the divergence and curl of the multicomponent seismograms (i.e., Sun et al. 2004). The above algorithms are often referred to as elastic wavefield decomposition (see Sun et al. 2001, 2004).

From a numerical modeling perspective approach, the pure P- and S-wavefields can be separated from full 
wavefield simulated by solving the first-order (velocitystress, i.e., Li et al. 2007) or second-order (displacementstress, i.e., Ma and Zhu 2003; Tang et al. 2012) elastodynamic equations of motion. At present, there is lacking a systematic comparison between the first- and second-order separated elastic wave equations in terms of computer memory requirements, computational efficiency and accuracy. For these reasons, we have undertaken such a comparative study of the numerical solutions and show the results here through the use of wavefield snapshots, common-source gather seismic sections, and synthetic seismograms. Four different approaches have been investigated, viz., the first-order separated elastic wave equation, the second-order separated elastic wave equation, the first-order full elastic wave equation, and the secondorder full elastic wave equation; a high-order staggered grid finite-difference method is used in all cases. Modeling results demonstrate the validity and effectiveness of two separated wave equations for simulating the pure P- and $\mathrm{S}$-wave fields directly.

\section{Overview of methodology}

In order to make a fair comparison, four different elastic wave equations were used in this paper; the first two equations are the first-order (velocity-stress) and the second-order (displacement-stress) full elastic wave equations, referred to as the mixed elastic wave equations (i.e., Alterman and Karal 1968). The latter two equations are the first-order (velocitystress) and second-order (displacement-stress) separated elastic wave equations, referred to as the separated elastic wave equations. In the following section we will briefly introduce the two separated elastic wave equations.

\subsection{The full (or mixed) elastic wave equations}

The first-order (velocity-stress) elastic equations of motion in a 2D isotropic medium can be expressed as (Virieux 1986),

$$
\begin{aligned}
& \rho \frac{\partial V_{x}}{\partial t}=\frac{\partial \tau_{x x}}{\partial x}+\frac{\partial \tau_{x z}}{\partial z}, \\
& \rho \frac{\partial V_{z}}{\partial t}=\frac{\partial \tau_{z z}}{\partial z}+\frac{\partial \tau_{x z}}{\partial x}, \\
& \frac{\partial \tau_{x x}}{\partial t}=c_{11} \frac{\partial V_{x}}{\partial x}+c_{13} \frac{\partial V_{z}}{\partial z}, \\
& \frac{\partial \tau_{z z}}{\partial t}=c_{13} \frac{\partial V_{x}}{\partial x}+c_{33} \frac{\partial V_{z}}{\partial z}, \\
& \frac{\partial \tau_{x z}}{\partial t}=c_{44} \frac{\partial V_{z}}{\partial x}+c_{44} \frac{\partial V_{x}}{\partial z} .
\end{aligned}
$$

The corresponding second-order (displacement-stress) equations of motion in a $2 \mathrm{D}$ isotropic medium can be written as (Virieux 1986),

$$
\begin{gathered}
\rho \frac{\partial^{2} U_{x}}{\partial t^{2}}=\frac{\partial \tau_{x x}}{\partial x}+\frac{\partial \tau_{x z}}{\partial z}, \\
\rho \frac{\partial^{2} U_{z}}{\partial t^{2}}=\frac{\partial \tau_{z z}}{\partial z}+\frac{\partial \tau_{x z}}{\partial x}, \\
\tau_{x x}=c_{11} \frac{\partial U_{x}}{\partial x}+c_{13} \frac{\partial U_{z}}{\partial z}, \\
\tau_{z z}=c_{13} \frac{\partial U_{x}}{\partial x}+c_{33} \frac{\partial U_{z}}{\partial z}, \\
\tau_{x z}=c_{44} \frac{\partial U_{z}}{\partial x}+c_{44} \frac{\partial U_{x}}{\partial z} .
\end{gathered}
$$

In the above equations, $V_{i}(i=x, z), U_{i}(i=x, z)$ and $\tau_{i j}(i, j=x, z)$ are particle velocity, displacement and stress components, respectively. $\rho$ is the medium density and $c_{i j}$ is the stiffness tensor. In an isotropic medium, there are only two independent elastic parameters and $c_{11}=c_{33}=$ $\lambda+2 \mu=\rho \alpha^{2}, c_{13}=\lambda, c_{44}=\mu=\rho \beta^{2}$, where $\lambda$ and $\mu$ are the bulk and shear modulus, respectively, and $\alpha$ and $\beta$ are the P- and S-wave velocities, respectively.

\subsection{The separated elastic wave equations}

In 2D isotropic media, we can express the $x$-component velocity $\left(V_{x}\right)$ and the $z$-component velocity $\left(V_{z}\right)$ of the mixed wavefield by different combinations of the compressional $\left(V_{\mathrm{P}}\right)$ and shear $\left(V_{\mathrm{S}}\right)$ waves of the separated wavefields as follows,

$$
\left\{\begin{array}{l}
V_{x}=V_{\mathrm{P}_{x}}+V_{\mathrm{S}_{x}} \\
V_{z}=V_{\mathrm{P}_{z}}+V_{\mathrm{S}_{z}}
\end{array}\right.
$$

Here $V_{\mathrm{P}_{x}}$ and $V_{\mathrm{S}_{x}}$ are the $x$-components of the separated Pand $\mathrm{S}$-waves, respectively, and $V_{\mathrm{P}_{z}}$ and $V_{\mathrm{S}_{z}}$ are the $z$ components of the separated P- and S-waves. We can then obtain the following first-order (velocity-stress) separated elastic wave equations for simulating pure $\mathrm{P}$ - and S-waves (i.e., Li et al. 2007),

$$
\left\{\begin{array}{l}
\rho \frac{\partial V_{\mathrm{P}_{x}}}{\partial t}=\frac{\partial \sigma_{\mathrm{P}_{x x}}}{\partial x} \\
\rho \frac{\partial V_{\mathrm{P}_{z}}}{\partial t}=\frac{\partial \sigma_{\mathrm{P}_{z z}}}{\partial z} \\
\frac{\partial \sigma_{\mathrm{P}_{x x}}}{\partial t}=\rho \alpha^{2}\left(\frac{\partial V_{x}}{\partial x}+\frac{\partial V_{z}}{\partial z}\right) \\
\frac{\partial \sigma_{\mathrm{P}_{z z}}}{\partial t}=\rho \alpha^{2}\left(\frac{\partial V_{x}}{\partial x}+\frac{\partial V_{z}}{\partial z}\right)
\end{array}\right.
$$




$$
\left\{\begin{array}{l}
\rho \frac{\partial V_{\mathrm{S}_{x}}}{\partial t}=\frac{\partial \sigma_{\mathrm{S}_{x x}}}{\partial x}+\frac{\partial \sigma_{\mathrm{S}_{x z}}}{\partial z} \\
\rho \frac{\partial V_{\mathrm{S}_{z}}}{\partial t}=\frac{\partial \sigma_{\mathrm{S}_{x z}}}{\partial x}+\frac{\partial \sigma_{\mathrm{S}_{z z}}}{\partial z} \\
\frac{\partial \sigma_{\mathrm{S}_{x x}}}{\partial t}=-2 \rho \beta^{2} \frac{\partial V_{z}}{\partial z} \\
\frac{\partial \sigma_{\mathrm{S}_{z z}}}{\partial t}=-2 \rho \beta^{2} \frac{\partial V_{x}}{\partial x} \\
\frac{\partial \sigma_{\mathrm{S}_{x z}}}{\partial t}=\rho \beta^{2}\left(\frac{\partial V_{x}}{\partial z}+\frac{\partial V_{z}}{\partial x}\right)
\end{array}\right.
$$

where $\sigma_{\mathrm{P}_{x x}}, \sigma_{\mathrm{P}_{z z}}, \sigma_{\mathrm{S}_{x x}}, \sigma_{\mathrm{S}_{z z}}$, and $\sigma_{\mathrm{S}_{x z}}$ are the stress components of the separated $\mathrm{P}$ - and $\mathrm{S}$-waves, respectively. It is easy to prove that for Eqs. (6) and (7) we have $\nabla \times \mathbf{V}_{P}=0, \nabla$. $\mathbf{V}_{\mathrm{S}}=0$, and $\mathbf{V}=\mathbf{V}_{P}+\mathbf{V}_{S}$ (e.g., Li et al. 2007).

In similar fashion to the above first-order separated elastic wave equations, we can express $x$-component of the displacement $\left(U_{x}\right)$ and the $z$-component of the displacement $\left(U_{z}\right)$ of the full (or mixed) wavefield by different displacement component combinations of the compressional $\left(U_{\mathrm{P}}\right)$ and shear $\left(U_{\mathrm{S}}\right)$ waves of the separated displacement wavefields as follows (i.e., Tang et al. 2012),

$\left\{\begin{array}{l}U_{x}=U_{\mathrm{P}_{x}}+U_{\mathrm{S}_{x}} \\ U_{z}=U_{\mathrm{P}_{z}}+U_{\mathrm{S}_{z}}\end{array}\right.$

where $U_{\mathrm{P}_{x}}$ and $U_{\mathrm{S}_{x}}$ are the $x$-component displacements of the separated $\mathrm{P}$ - and S-waves, respectively, and $U_{\mathrm{P}_{z}}$ and $U_{\mathrm{S}_{z}}$ are the $z$-component displacements of the separated Pand S-waves. Therefore, we can also obtain the secondorder (displacement-stress) separated elastic wave equations as follows

$$
\begin{gathered}
\left\{\begin{array}{l}
\rho \frac{\partial^{2} U_{\mathrm{P}_{x}}}{\partial t^{2}}=\frac{\partial \sigma_{\mathrm{P}_{x x}}}{\partial x}, \\
\rho \frac{\partial^{2} U_{\mathrm{P}_{z}}}{\partial t^{2}}=\frac{\partial \sigma_{\mathrm{P}_{z z}}}{\partial z}, \\
\sigma_{\mathrm{P}_{x x}}=\rho \alpha^{2}\left(\frac{\partial U_{x}}{\partial x}+\frac{\partial U_{z}}{\partial z}\right) \\
\sigma_{\mathrm{P}_{z z}}=\rho \alpha^{2}\left(\frac{\partial U_{x}}{\partial x}+\frac{\partial U_{z}}{\partial z}\right) \\
\rho \frac{\partial^{2} U_{\mathrm{S}_{x}}}{\partial t^{2}}=\frac{\partial \sigma_{\mathrm{S}_{x x}}}{\partial x}+\frac{\partial \sigma_{\mathrm{S}_{x z}}}{\partial z} \\
\rho \frac{\partial^{2} U_{\mathrm{S}_{z}}}{\partial t^{2}}=\frac{\partial \sigma_{\mathrm{S}_{x z}}}{\partial x}+\frac{\partial \sigma_{\mathrm{S}_{z z}}}{\partial z} \\
\sigma_{\mathrm{S}_{x x}}=-2 \rho \beta^{2} \frac{\partial U_{z}}{\partial z} \\
\sigma_{\mathrm{S}_{z z}}=-2 \rho \beta^{2} \frac{\partial U_{x}}{\partial x} \\
\sigma_{\mathrm{S}_{x z}}=\rho \beta^{2}\left(\frac{\partial U_{x}}{\partial z}+\frac{\partial U_{z}}{\partial x}\right)
\end{array}\right.
\end{gathered}
$$

As for Eqs. (6) and (7), we can also prove that $\nabla \times \mathbf{U}_{P}=0, \nabla \cdot \mathbf{U}_{s}=0$ and $\mathbf{U}=\mathbf{U}_{P}+\mathbf{U}_{S}$ (e.g., Tang et al. 2012).

\section{Source and boundary conditions}

\subsection{Source loading}

In our simulation tests, we use vector force source. The force direction is in the $x$ direction. The source is a Ricker wavelet. Note that for easy comparison, in the first-order (velocity-stress) equations, we added velocity Ricker wavelet as the source, and while in the second-order (displacement-stress) equations, we added displacement Ricker wavelet as source. In the following specification, the source is centered at the position $\left(x_{0}, z_{0}\right)$ but distributed over an area given by the Gaussian function, with attenuation $\kappa_{0}$

$$
\begin{aligned}
f(x, z, t)= & \left\{1-2\left[\pi f_{0}\left(t-\frac{1.5}{f_{0}}\right)\right]^{2}\right\} e^{-\left[\pi f_{0}\left(t-\frac{1.5}{f_{0}}\right)\right]^{2}} \\
& \times e^{\left\{-\kappa_{0}\left[\left(x-x_{0}\right)^{2}+\left(z-z_{0}\right)^{2}\right]\right\}}
\end{aligned}
$$

where $f_{0}$ is the center frequency of the wavelet. In the numerical simulations we set $\kappa_{0}=0.1$.

\subsection{Boundary conditions}

An absorbing boundary condition is added to all model boundaries. Based on the non-reflecting and absorbing boundary formulation of Cerjan et al. (1985), we designed a revised attenuating boundary condition (Tang et al. 2012),

$G_{\mathrm{b}}=\mathrm{e}^{-[\gamma(N-i)]^{2}}$,

$G_{\mathrm{c}}=\mathrm{e}^{-\gamma\left[\left(i-i_{0}\right)^{2}+\left(j-j_{0}\right)^{2}\right]}$,

where $\gamma$ is the attenuation factor, $N$ is the grid number of the absorbing boundary, $(i, j)$ represents the grid point in the $x$ and $z$ directions and $\left(i_{0}, j_{0}\right)$ is the grid point of the corner node in $x$ and $z$ directions, respectively. Note that the above absorbing boundary condition (12 and 13) is applied to all four different modeling approaches.

\subsection{Computational stability}

In $2 \mathrm{D}$ transversely isotropic media the computational stability condition for temporal order $2 \mathrm{M}$ and spatial order $2 \mathrm{~N}$ in staggered grid finite-difference modeling is given by (e.g., Dong et al. 2000),

$$
\begin{aligned}
& 0 \leq \sum_{m=1}^{M} \frac{(-1)^{m-1}}{(2 m-1) !} L_{x}^{2 m} d^{2 m} \leq 1, \\
& 0 \leq \sum_{m=1}^{M} \frac{(-1)^{m-1}}{(2 m-1) !} L_{z}^{2 m} d^{2 m} \leq 1,
\end{aligned}
$$

where $L_{x}, L_{z}$, and $d$ take the following forms 


$$
\begin{aligned}
L_{x} & =\sqrt{\frac{\Delta t^{2}}{\Delta x^{2}} \frac{(\lambda+2 \mu)}{\rho}+\frac{\Delta t^{2}}{\Delta z^{2}} \frac{\mu}{\rho}}, \\
L_{z} & =\sqrt{\frac{\Delta t^{2}}{\Delta x^{2}} \frac{\mu}{\rho}+\frac{\Delta t^{2}}{\Delta z^{2}} \frac{(\lambda+2 \mu)}{\rho}}, \\
d & =\sum_{n-1}^{N} C_{n}^{(N)}(-1)^{n-1},
\end{aligned}
$$

where $\rho$ is density, $\Delta x$ and $\Delta z$ are the grid intervals along the $x$ and $z$ directions, respectively, $\Delta t$ is the time step interval and $C_{n}^{(N)}$ is the differential coefficient. In our case, with the second-order accuracy in time $(M=1)$, and the 18th-order accuracy in space $(N=9)$, the stability condition is,

$0 \leq L_{x}^{2} d^{2} \leq 1$,

$0 \leq L_{z}^{2} d^{2} \leq 1$

$$
\begin{aligned}
L_{x} & =\sqrt{\frac{\Delta t^{2}}{\Delta x^{2}} \frac{(\lambda+2 \mu)}{\rho}+\frac{\Delta t^{2}}{\Delta z^{2}} \frac{\mu}{\rho}} \\
L_{z} & =\sqrt{\frac{\Delta t^{2}}{\Delta x^{2}} \frac{\mu}{\rho}+\frac{\Delta t^{2}}{\Delta z^{2}} \frac{(\lambda+2 \mu)}{\rho}}, \\
d & =\sum_{n-1}^{9} C_{n}^{(9)}(-1)^{n-1} .
\end{aligned}
$$

\section{Computational efficiency and accuracy}

To evaluate the computational accuracy and efficiency, we select a 2D uniform model of size of $490 \mathrm{~m} \times 490 \mathrm{~m}$. For comparison purposes, we use three different cell sizes $(2.5 \mathrm{~m} \times 2.5 \mathrm{~m}, 5.0 \mathrm{~m} \times 5.0 \mathrm{~m}$, and $10 \mathrm{~m} \times 10 \mathrm{~m})$ to parameterize the velocity model. In general, the memory requirements for separate equations are slightly larger than that of full-wave equations for a specific cell-sized model, due to more variables in the separate equations. The computer we used here is a Laptop (AMD Phenom-II N850-2.2 GHz). The CPU time consumption for the two (first-order and second-order) separate equations are nearly the same for both (see Table 1), as is the CPU time consumption for the two (first-order and second-order) mixed equations. However, the separate equations take almost $50 \%$ longer to run than do the mixed equations. To assess computational accuracy, we calculated travel times at every node within the model and compared them with the corresponding analytic solutions. The average travel time errors are listed in Table 1 for the four different approaches for the direct P- and S-waves. In general, the computational accuracy of the numerical solutions for all four approaches is at the same level, but drops with an increase in the cell size used in the model parameterization (see Table 1).

\section{Numerical tests of wavefield simulations}

For comparison purposes, two different velocity models are selected, the first is a two-layered model and the second is a three-layered fault model. For each model four different kinds of wave equations are used to simulate the seismic wavefields with a high-order (second-order temporal and 18th-order spatial accuracy) staggered grid finite-difference method. The corresponding results are shown through the wavefield snapshots, common-source gather seismic sections, and synthetic seismograms.

\subsection{Two-layered model}

The model dimension is $1,990 \mathrm{~m} \times 1,990 \mathrm{~m}$, and the cell

\begin{tabular}{|c|c|c|c|c|c|c|c|c|c|c|c|c|}
\hline \multirow[t]{3}{*}{ Cell size } & \multicolumn{4}{|c|}{ CPU time (s) } & \multicolumn{8}{|c|}{ Computational accuracy (ms) } \\
\hline & \multicolumn{2}{|c|}{ Separated } & \multicolumn{2}{|l|}{ Mixed } & \multicolumn{2}{|c|}{ Mixed after separated } & \multicolumn{2}{|c|}{ Mixed } & \multicolumn{4}{|c|}{ Separated } \\
\hline & $V$ & $U$ & $V$ & $U$ & $V$ & $U$ & $V$ & $U$ & $V_{\mathrm{P}}$ & $U_{\mathrm{P}}$ & $V_{\mathrm{S}}$ & $U_{\mathrm{S}}$ \\
\hline $2.5 \mathrm{~m} \times 2.5 \mathrm{~m}$ & 48.88 & 48.56 & 38.45 & 37.20 & 1.25 & 1.25 & 1.25 & 1.25 & 1.25 & 1.25 & 1.00 & 1.00 \\
\hline $5 \mathrm{~m} \times 5 \mathrm{~m}$ & 7.70 & 7.65 & 6.06 & 5.85 & 3.25 & 3.25 & 3.25 & 3.25 & 3.25 & 3.25 & 3.00 & 3.00 \\
\hline $10 \mathrm{~m} \times 10 \mathrm{~m}$ & 1.13 & 1.09 & 0.78 & 0.72 & 7.00 & 7.00 & 7.00 & 7.00 & 7.75 & 7.75 & 5.75 & 5.75 \\
\hline
\end{tabular}
size used in the parameterization is $10 \mathrm{~m} \times 10 \mathrm{~m}$. This model incorporates a horizontal boundary at $z=1,190 \mathrm{~m}$, which separates the upper layer of model parameters $\alpha=3,000 \mathrm{~m} / \mathrm{s}, \quad \beta=1,800 \mathrm{~m} / \mathrm{s}, \quad$ and $\rho=2,000 \mathrm{~kg} / \mathrm{m}^{3}$,

Table 1 CPU time consumption and computational accuracy tests for four different

Modeling approaches with varying cell size in the model parameterization. In the table, the "separated" indicates the results obtained by the separate elastic wave equations, the "mixed" indicates the results obtained by full elastic wave equations, and the "stacked after separated" represents the results obtained by stacking the pure $\mathrm{P}$ and $\mathrm{S}$ results 


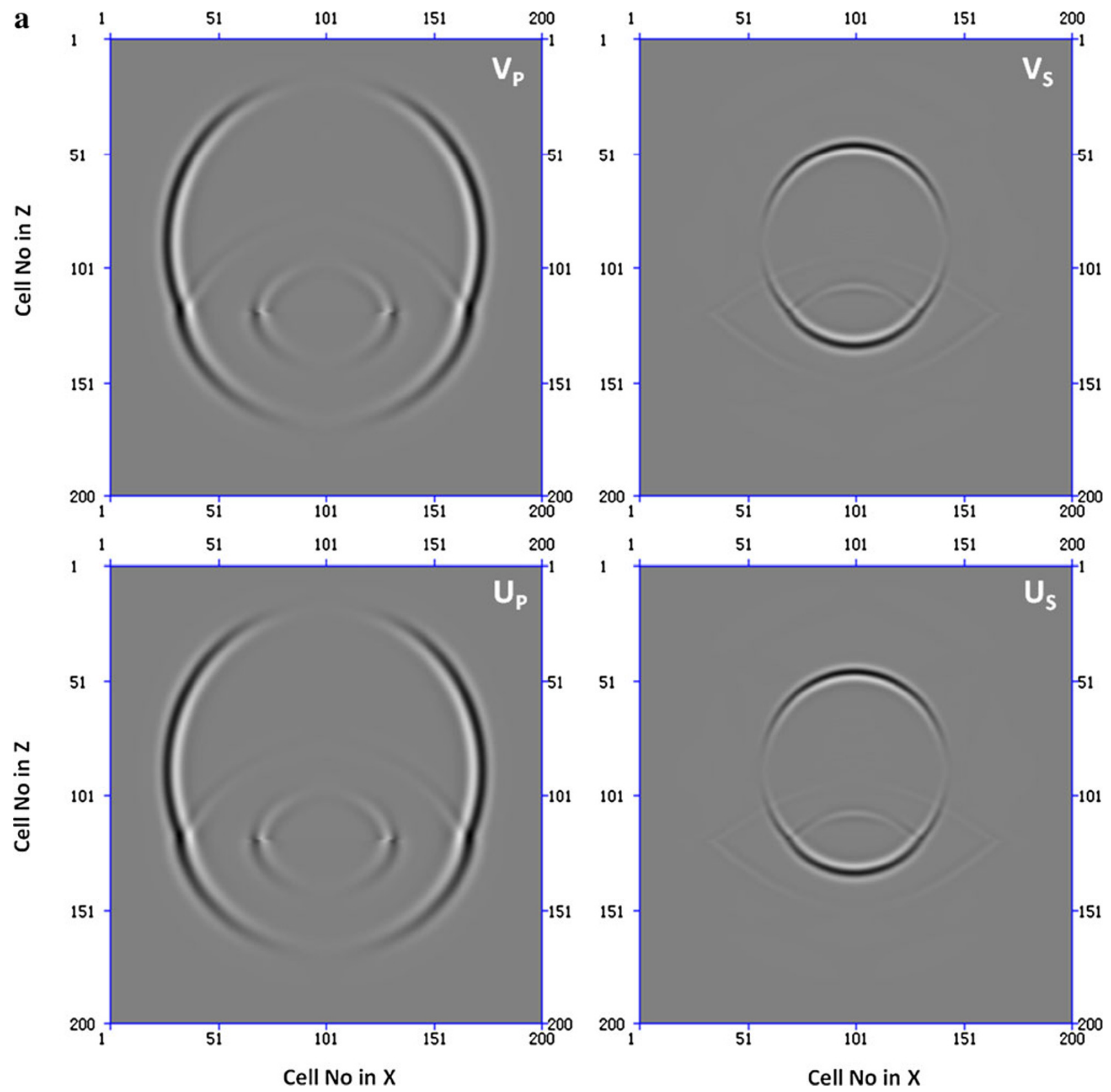

Fig. 1 a The wavefield snapshot $(t=300 \mathrm{~ms})$ of $x$-component for two-layered velocity model. In the figure $V_{\mathrm{P}}$ and $V_{\mathrm{S}}, U_{\mathrm{P}}$ and $U_{\mathrm{S}}$ represent the results obtained by the first-order (Eqs. 6-7) and second-order (Eqs. 9-10) separate elastic wave equations, respectively. These captions are applied for all following diagrams and figures. b Similar to (a), but obtained by the two full elastic wave equation approaches and plus stacked results of $V_{\mathrm{P}}+V_{\mathrm{S}}$ and $U_{\mathrm{P}}+U_{\mathrm{S}}$. In the figure, the number from 1 to 10 indicates different seismic phases: 1 direct $\mathrm{P}, 2$ direct $\mathrm{S}, 3$ pure reflected $\mathrm{P}_{1} \mathrm{P}^{1}, 4$ reflected and converted $\mathrm{P}_{1} \mathrm{~S}^{1}, 5$ reflected and converted $\mathrm{S}_{1} \mathrm{P}^{1}, 6$ pure reflected $\mathrm{S}_{1} \mathrm{~S}^{1}, 7$ pure transmitted $\mathrm{S}_{1} \mathrm{~S}_{2}, 8$ transmitted and converted $\mathrm{S}_{1} \mathrm{P}_{2} ; 9$ transmitted and converted $\mathrm{P}_{1} \mathrm{~S}_{1}$, and 10 pure transmitted $\mathrm{P}_{1} \mathrm{P}_{2}$ phase

from the lower layer having $\alpha=3,500 \mathrm{~m} / \mathrm{s}$, $\beta=2,060 \mathrm{~m} / \mathrm{s}$, and $\rho=2,200 \mathrm{~kg} / \mathrm{m}^{3}$. The time sampling interval is set at $1 \mathrm{~ms}$ and the source, of dominant frequency $25 \mathrm{~Hz}$, is located at $x=990 \mathrm{~m}$ and $z=890 \mathrm{~m}$. For simplicity, in our phase convention: $\mathrm{P}$ or $\mathrm{S}$ represents a P- or S-wave, respectively, and the number in the subscript or superscript indicates a downward or upward propagating seismic wave in the different layers, given by the number, respectively (for more details, see Bai et al. 2009). 

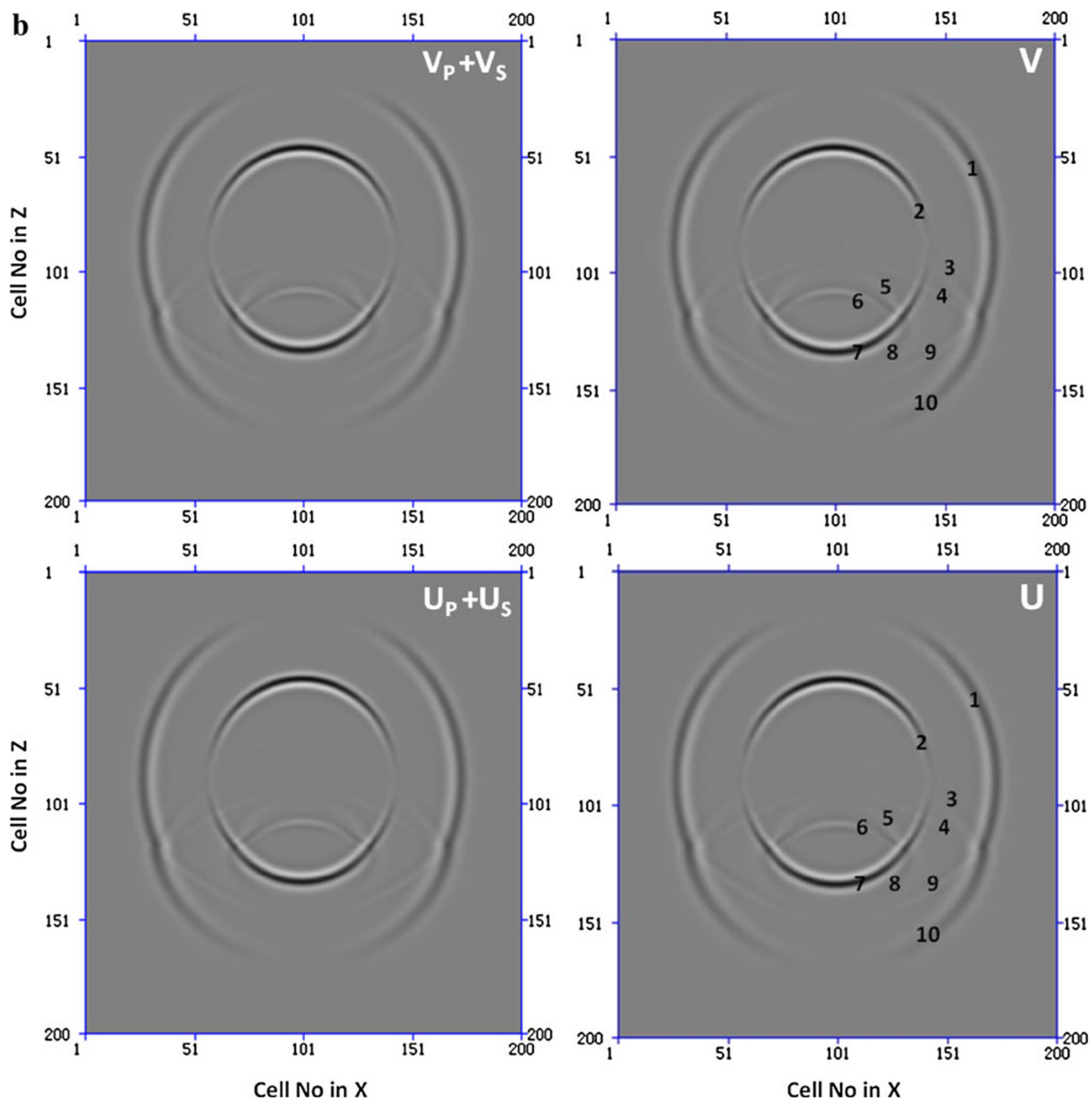

Fig. 1 continued

Figure 1a shows the $x$-component wavefield snapshot obtained by the first-order separate (upper panels, referred as $V_{\mathrm{P}}$ and $V_{\mathrm{S}}$ ) and the second-order separate (lower panels, referred as $U_{\mathrm{P}}$ and $U_{\mathrm{S}}$ ) equations, whereas Fig. $1 \mathrm{~b}$ displays the snapshots obtained by the first-order mixed (upper right panel, referred as $V$ ) and the second-order mixed (lower right panel, referred as $U$ ) equations, plus the stacked $V_{\mathrm{P}}+V_{\mathrm{S}}$ (upper left panel) and $U_{\mathrm{P}}+U_{\mathrm{S}}$ (lower left panel) results. It is clearly visible from Fig. 1 that (1) both snapshots for pure $\mathrm{P}$-waves on the last segment of the path (including direct $\mathrm{P}, \mathrm{P}_{1} \mathrm{P}^{1}, \mathrm{P}_{1} \mathrm{P}_{2}, \mathrm{~S}_{1} \mathrm{P}^{1}$, and $S_{1} P_{2}$ ) and pure $S$-waves on the last segment of the path (including direct $S, S_{1} S^{1}, S_{1} S_{2}, P_{1} S^{1}$, and $P_{1} S_{2}$ ) are equal for both the first-order and second-order separate 

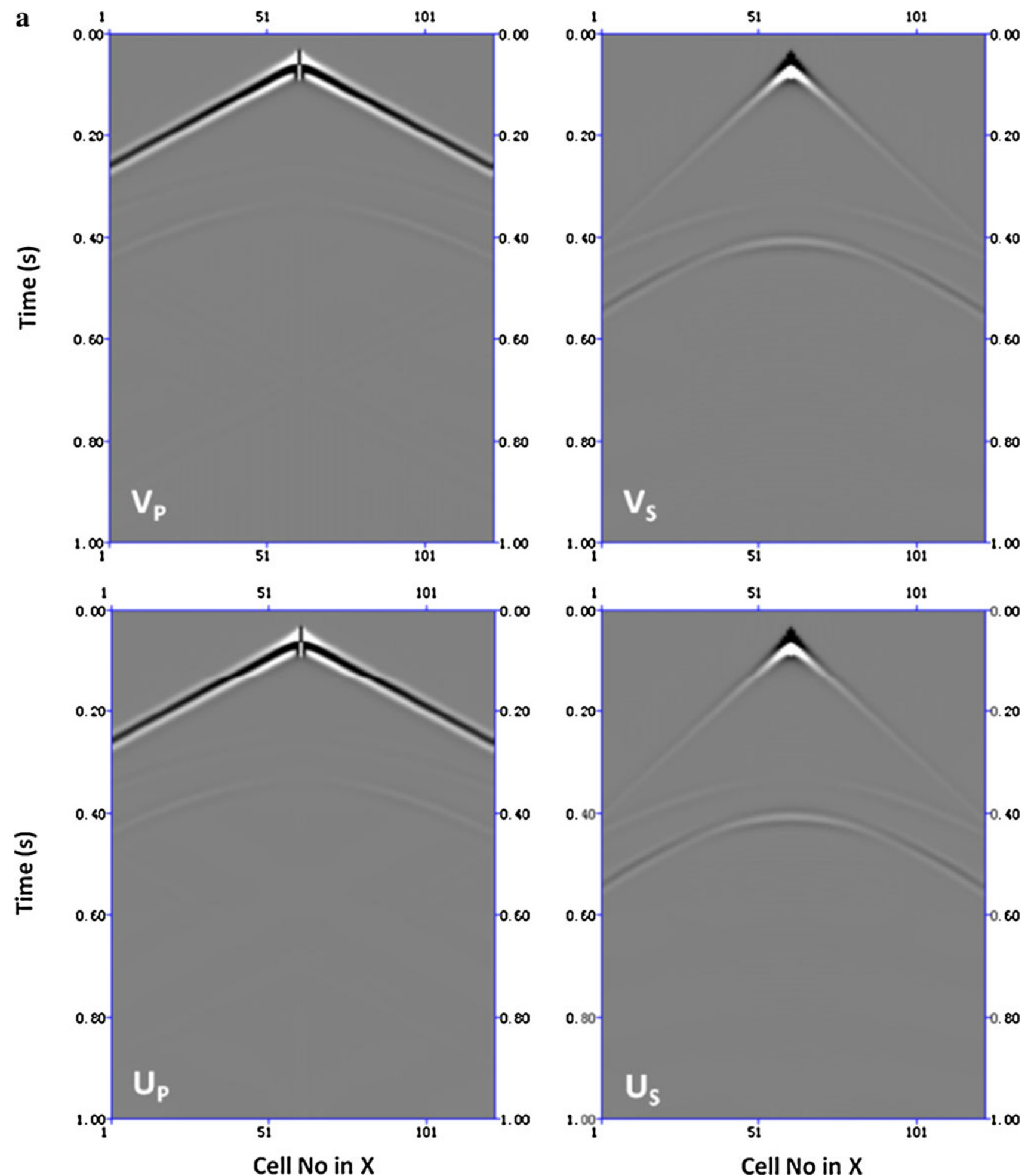

\section{Cell No in X}

Fig. 2 a The common-source gather seismic section of $x$-component (receiver line at $z=890 \mathrm{~m}$ with receiver spacing of $10 \mathrm{~m}$ ) for the twolayered velocity model obtained by the two different (first-order and second-order) separated elastic wave equation approaches. b Similar to (a), but obtained by the two different separate elastic wave equation approaches and plus the stacked results of $V_{\mathrm{P}}+V_{\mathrm{S}}$ and $U_{\mathrm{P}}+\mathrm{U}_{\mathrm{S}}$. In the figure the number 1 for direct $\mathrm{P}, 2$ for direct $\mathrm{S}, 3$ for reflected $\mathrm{P}_{1} \mathrm{P}^{1}, 4$ for reflected and converted $\mathrm{P}_{1} \mathrm{~S}^{1} / \mathrm{S}_{1} \mathrm{P}^{1}$, and 5 for reflected $\mathrm{S}_{1} \mathrm{~S}^{1}$ phases 

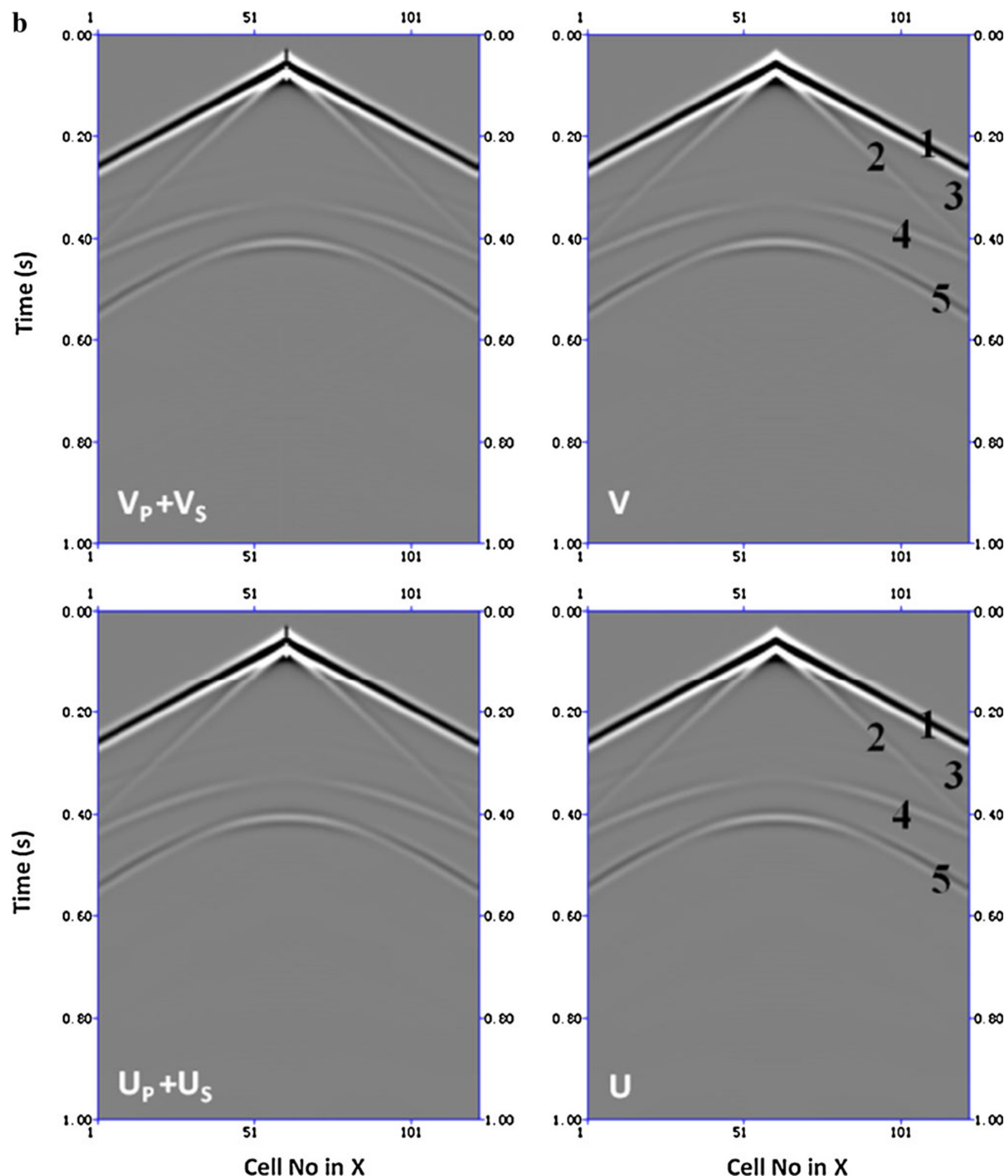

Cell No in X

Fig. 2 continued

equations. Also, the stacked wavefield snapshots $\left(V_{\mathrm{P}}+V_{\mathrm{S}}\right.$ or $\left.U_{\mathrm{P}}+U_{\mathrm{S}}\right)$ are similar to the mixed wavefield snapshots $(V$ or $U)$ in each case. Figure 2a displays the common-source gather seismic sections for the $x$-component (receiver line at the $X=890 \mathrm{~m}$ at $10 \mathrm{~m}$ interval) calculated by the first-order separate $\left(V_{\mathrm{P}}\right.$ and $\left.V_{\mathrm{S}}\right)$ and 

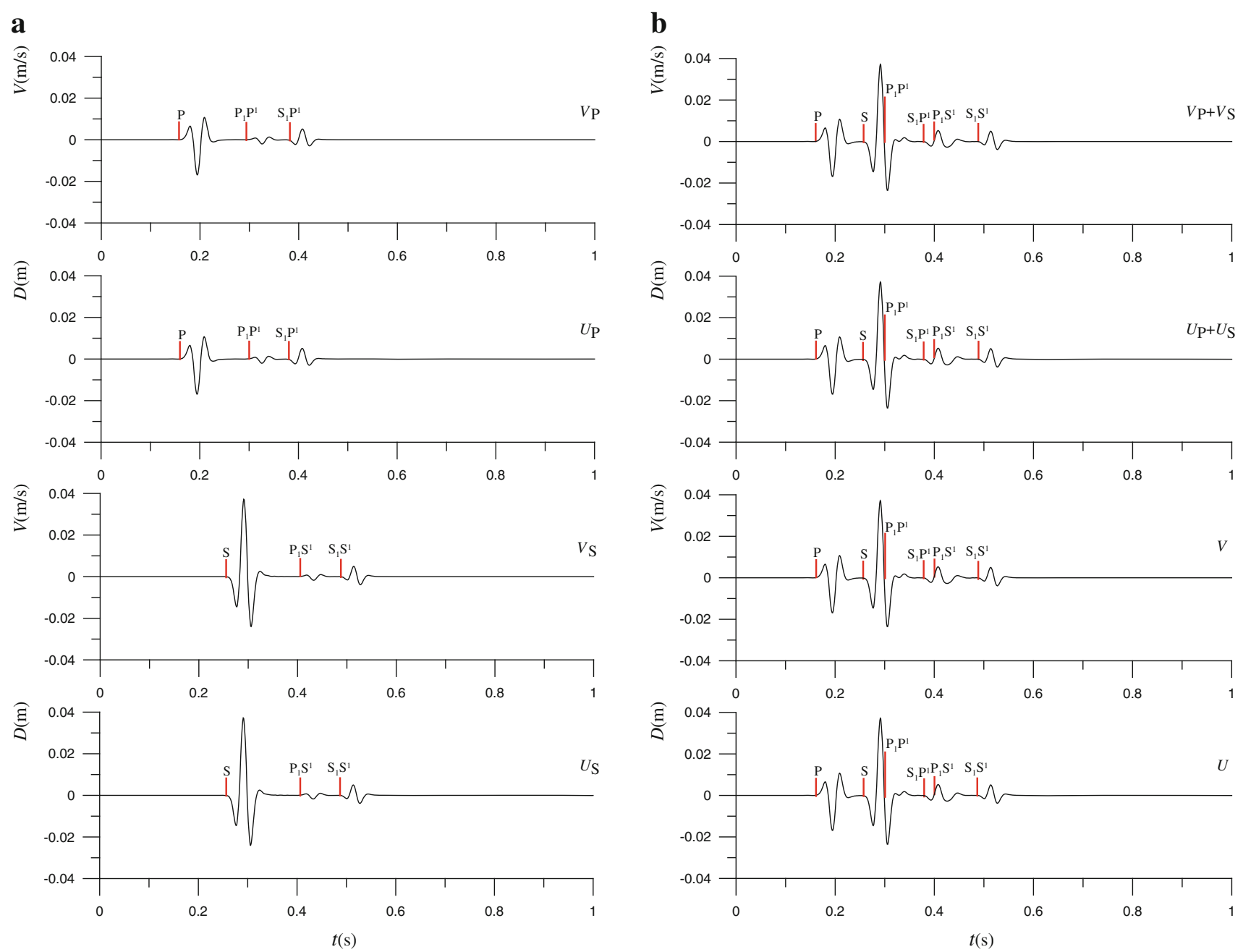

Fig. 3 a The $z$-component synthetic seismogram at location $(x=1390 \mathrm{~m}$ and $z=790 \mathrm{~m})$ obtained by the two different separate elastic wave equation approaches for the two-layered velocity model. In the figure and the following synthetic seismograms, the red vertical bar indicates the travel times of the corresponding seismic phases calculated by a multistage MSPM algorithm. b Similar to (a), but obtained by the two full elastic wave equation approaches and plus the stacked results of $V_{\mathrm{P}}+V_{\mathrm{S}}$ and $U_{\mathrm{P}}+U_{\mathrm{S}}$

second-order separate $\left(U_{\mathrm{P}}\right.$ and $\left.U_{\mathrm{S}}\right)$ equations. Figure $2 \mathrm{~b}$ shows the shot gathers obtained by the first-order mixed $(V)$ and second-order mixed $(U)$ equations, and plus the stacked $V_{\mathrm{P}}+V_{\mathrm{S}}$ and $U_{\mathrm{P}}+U_{\mathrm{S}}$ gathers. Similar conclusions about the seismic sections in Fig. 2 can be drawn as was done for the snapshots in Fig. 1, regarding equivalence of working with stacked separate $\mathrm{P}$ and $\mathrm{S}$ results or mixed results with the first-order or secondorder wave equations used for obtaining the seismic sections.

Figure 3a shows in greater detail the $z$-component synthetic seismograms (particle displacements and particle velocities) at location $(x=1,390 \mathrm{~m}$ and $z=790 \mathrm{~m})$ obtained by the first-order separate $\left(V_{\mathrm{P}}\right.$ and $\left.V_{\mathrm{S}}\right)$ and second-order $\left(U_{\mathrm{P}}\right.$ and $\left.U_{\mathrm{S}}\right)$ separate equations, with compar- ison results from the first- and second-order mixed equations given in Fig. 3b. For further comparison, the travel times of each phase are computed using our recently developed ray-tracing algorithm (multistagemodified shortest path method, referred as the multistage MSPM, Bai et al. 2009) and the corresponding results are indicated by a short red vertical bar in the figure. It is clearly seen from Fig. 3 that the seismograms for pure P (including direct $\mathrm{P}$, primary reflected $\mathrm{P}_{1} \mathrm{P}^{1}$, and primary reflected and converted $\mathrm{P}_{1} \mathrm{~S}^{1}$ ) and pure $\mathrm{S}$ (including direct $S$, primary reflected $S_{1} S^{1}$, and primary reflected and converted $\mathrm{S}_{1} \mathrm{P}^{1}$ ) waves are the same using either the firstorder (velocity) or second-order (displacement) separate equations. Furthermore, the mixed field equations give the same results as adding the separate field equation results. 


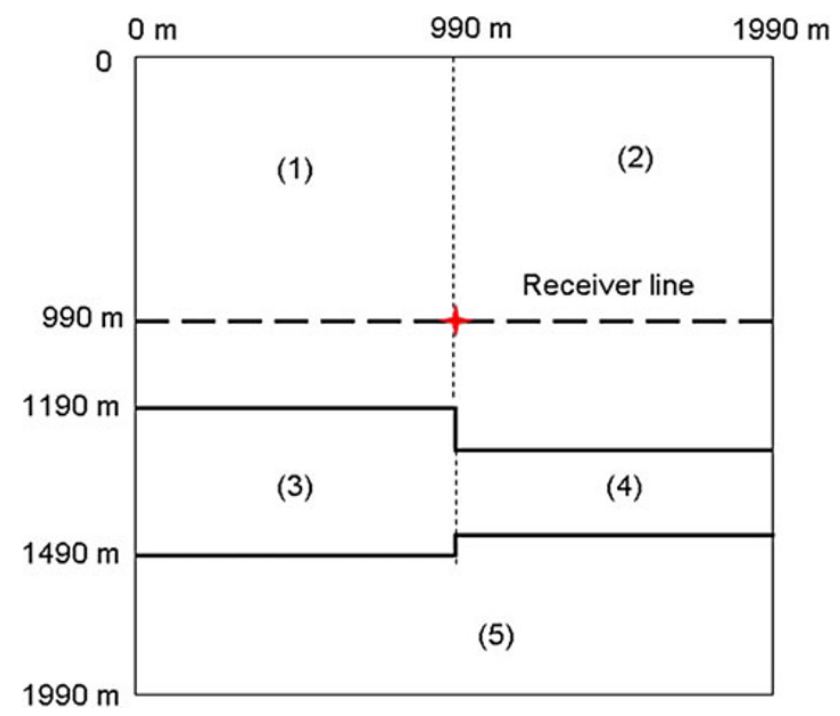

Fig. 4 Diagram showing a three-layered fault model, in which the model is divided into five regions by two fault-like interfaces. In figure, the red cross indicates the source location and 100 receivers located along the receiver line with $10-\mathrm{m}$ spacing interval

Table 2 The model parameters for the three-layered fault model

\begin{tabular}{llll}
\hline & $V_{\mathrm{P}}(\mathrm{m} / \mathrm{s})$ & $V_{\mathrm{S}}(\mathrm{m} / \mathrm{s})$ & $\rho\left(\mathrm{kg} / \mathrm{m}^{3}\right)$ \\
\hline Region 1 & 3,500 & 2,059 & 2.6 \\
Region 2 & 3,600 & 2,118 & 2.4 \\
Region 3 & 3,800 & 2,235 & 2.2 \\
Region 4 & 4,000 & 2,353 & 2.0 \\
Region 5 & 3,400 & 2,000 & 2.8 \\
\hline
\end{tabular}

The onset times of the various $\mathrm{P}$ - and $\mathrm{S}$-wave phases coincide with the indicated travel times (a short red vertical bar) predicted by the multistage MSPM ray-tracing algorithm.

\subsection{Three-layered fault model}

The model scale, cell size, time sampling interval, and source frequency are the same as in the Sect. 5.1. The model is a three-layered model, but with two fault-like interfaces embedded (see Fig. 4) and further the model is divided into five regions with different model parameters (see Table 2 for details). The source and receiver lines are indicated in Fig. 4.

Figure 5a shows $x$-component wavefield snapshot obtained by the first-order separate $\left(V_{\mathrm{P}}\right.$ and $\left.V_{\mathrm{S}}\right)$ and second-order separate ( $U_{\mathrm{P}}$ and $U_{\mathrm{S}}$ ) equations, and Fig. $5 \mathrm{~b}$ is the corresponding results obtained by the first-order mixed $(V)$ and second-order mixed $(U)$ equations, and plus the stacked $V_{\mathrm{P}}+V_{\mathrm{S}}$ and $U_{\mathrm{P}}+U_{\mathrm{S}}$ results. Despite the presence of more complicated wavefields due to the fault-like interfaces, same conclusions can also be drawn from Fig. 5 as in Fig. 1. The separated P-wave fields (include direct $\mathrm{P}$, primary reflected $\mathrm{P}_{1} \mathrm{P}^{1}$, primary reflected and converted $\mathrm{P}_{1} \mathrm{~S}_{2} \mathrm{P}^{2}$ and $\mathrm{P}_{1} \mathrm{~S}_{2} \mathrm{P}^{2} \mathrm{P}^{1}$, pure transmitted $\mathrm{P}_{1} \mathrm{P}_{2}$ and $\mathrm{P}_{1} \mathrm{P}_{2} \mathrm{P}_{3}$, etc.) and $\mathrm{S}$-wave fields (include direct $\mathrm{S}$, primary reflected $S_{1} S^{1}$ and $S_{1} S_{2} S^{2}$, primary reflected and converted $\mathrm{P}_{1} \mathrm{~S}^{1}$ and $\mathrm{P}_{1} \mathrm{P}_{2} \mathrm{~S}^{2}$, pure transmitted $\mathrm{S}_{1} \mathrm{~S}_{2}$, transmitted and converted $\mathrm{P}_{1} \mathrm{~S}_{2}, \mathrm{P}_{1} \mathrm{P}_{2} \mathrm{~S}_{3}$ and $\mathrm{P}_{1} \mathrm{P}_{2} \mathrm{~S}_{3}$, etc.) are the same regardless of the first-order or second-order separate equations applied for simulation. Furthermore, the stacked wavefields $\left(V_{\mathrm{P}}+V_{\mathrm{S}}\right.$ or $\left.U_{\mathrm{P}}+U_{\mathrm{S}}\right)$ from the pure $\mathrm{P}\left(V_{\mathrm{P}}\right.$ or $\left.U_{\mathrm{P}}\right)$ and $\mathrm{S}\left(V_{\mathrm{S}}\right.$ or $\left.U_{\mathrm{S}}\right)$ wavefields are the same as the mixed ( $V$ or $U$ ) wavefield, no matter whether the first-order or second-order mixed equations are used for simulation.

Figure 6a displays a common-source point gather seismic section for $x$-component (receiver line at $z=990 \mathrm{~m}$ with $10-\mathrm{m}$ interval) obtained by the first-order separate $\left(V_{\mathrm{P}}\right.$ and $\left.V_{\mathrm{S}}\right)$ and second-order separate $\left(U_{\mathrm{P}}\right.$ and $U_{\mathrm{S}}$ ), and while Fig. $6 \mathrm{~b}$ is the corresponding results obtained by the first-order mixed $(V)$ and second-order mixed $(U)$ equations, and plus the stacked $V_{\mathrm{P}}+V_{\mathrm{S}}$ and $U_{\mathrm{P}}+U_{\mathrm{S}}$ results. Besides the presence of more complicated seismic sections, same conclusions can also be drawn from Fig. 6 as in Fig. 2. Figure 7a shows a $z$ component synthetic seismogram at location $(x=690 \mathrm{~m}$, $z=890 \mathrm{~m}$ ) simulated by the first-order and second-order separate equations, and Fig. $7 \mathrm{~b}$ is the corresponding results obtained by the first-order and second-order mixed equations, and plus the stacked $V_{\mathrm{P}}+V_{\mathrm{S}}$ and $U_{\mathrm{P}}+U_{\mathrm{S}}$ results. In Fig. 7 the separate $\mathrm{P}$-wave phases include direct $\mathrm{P}$, reflected $\mathrm{P}_{1} \mathrm{P}^{1}$ and $\mathrm{P}_{1} \mathrm{P}_{2} \mathrm{P}^{2} \mathrm{P}^{1}$, and reflected and converted $\mathrm{S}_{1} \mathrm{P}^{1}, \mathrm{~S}_{1} \mathrm{P}_{2} \mathrm{P}^{2} \mathrm{P}^{1}, \mathrm{~S}_{1} \mathrm{P}_{2} \mathrm{~S}^{2} \mathrm{P}^{1}$, and $\mathrm{S}_{1} \mathrm{~S}_{2} \mathrm{~S}^{2} \mathrm{P}^{1}$; and the separate $S$-wave phases include direct $S$, reflected $\mathrm{S}_{1} \mathrm{~S}^{1}$ and $\mathrm{S}_{1} \mathrm{~S}_{2} \mathrm{~S}^{2} \mathrm{~S}^{1}$, and reflected and converted $\mathrm{P}_{1} \mathrm{~S}^{1}$, $\mathrm{P}_{1} \mathrm{~S}_{2} \mathrm{P}^{2} \mathrm{~S}^{1}$, and $\mathrm{P}_{1} \mathrm{~S}_{2} \mathrm{~S}^{2} \mathrm{~S}^{1}$, which are the same regardless of the first-order or second-order separate equations used for obtaining synthetic seismograms. For these clearly separate $\mathrm{P}$ and $\mathrm{S}$ synthetic seismograms, the predicted travel times for each phase are coincided with the corresponding onset times of the synthetic seismograms. The stacked synthetic seismograms $\left(V_{\mathrm{P}}+V_{\mathrm{S}}\right.$ or $\left.U_{\mathrm{P}}+U_{\mathrm{S}}\right)$ are similar to the mixed synthetic seismograms ( $V$ or $U$ ), but the onset time for each phase is no longer visible, due to the stacked energy content between the two or more nearby phases; for example, the onset of the direct $S$ arrival is clearly visible in the separate $S$ synthetic seismograms $\left(V_{\mathrm{S}}\right.$ or $\left.U_{\mathrm{S}}\right)$, but not on the stacked $\left(V_{\mathrm{P}}+V_{\mathrm{S}}\right.$ or $\left.U_{\mathrm{P}}+U_{\mathrm{S}}\right)$ or mixed $(V$ or $U$ ) synthetic seismograms. With the separate $\mathrm{P}$ - or $\mathrm{S}$-wavefield it is easy to recognize the different 

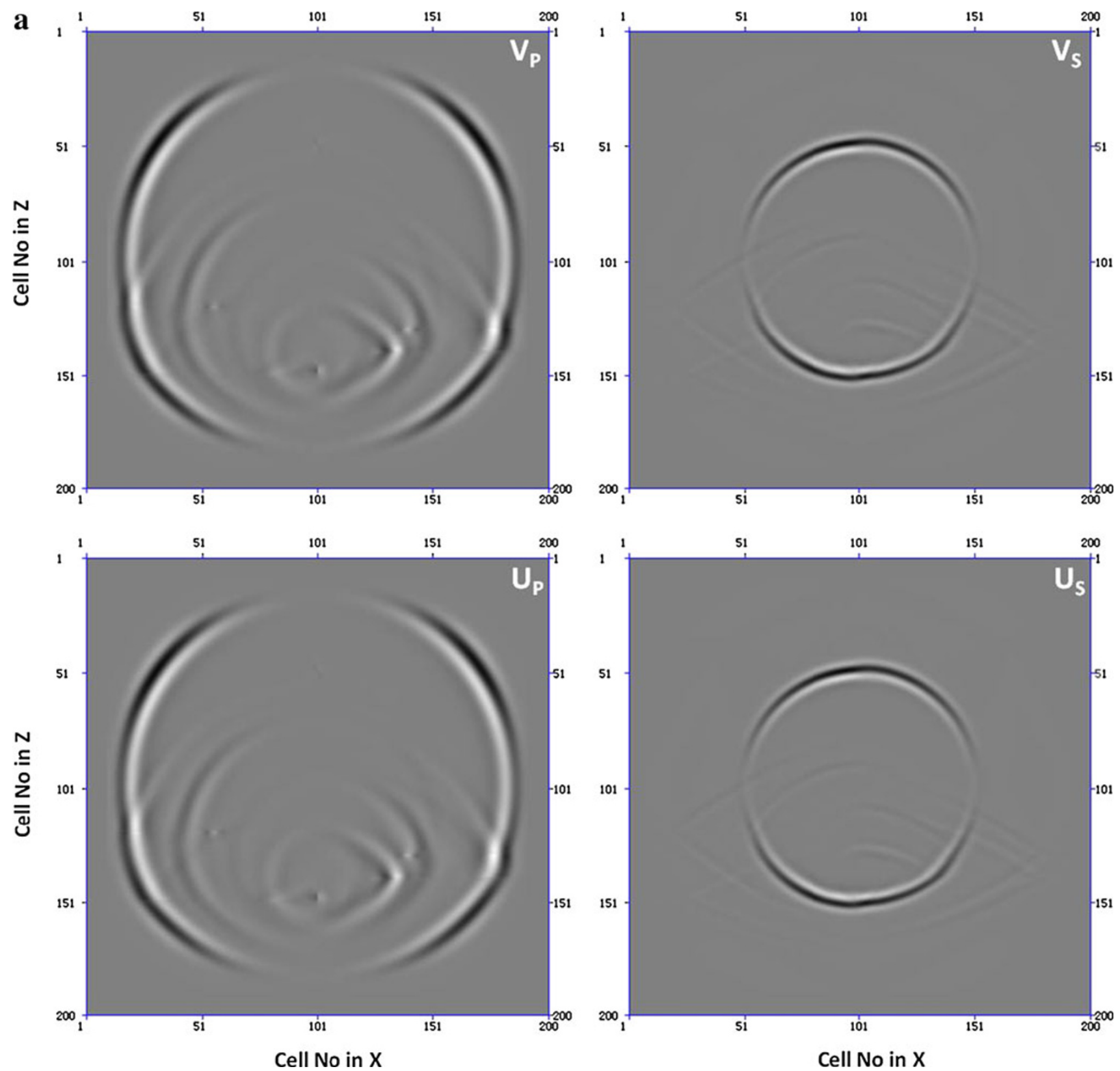

Fig. 5 a Similar to Fig. 1a, but for a three-layered fault model at $z$-component ( $t=320 \mathrm{~ms}$ ) obtained by the two different separate elastic wave equation approaches. b Similar to (a), but obtained by the two different separate elastic wave equation approaches and plus the stacked results of $V_{\mathrm{P}}+V_{\mathrm{S}}$ and $U_{\mathrm{P}}+U_{\mathrm{S}}$. In the figure, the number 1 is for $\mathrm{P}, 2$ is for $\mathrm{S}, 3$ is for $\mathrm{P}_{1} \mathrm{P}^{1}, 4$ is for $\mathrm{P}_{1} \mathrm{~S}^{1}, 5$ is for $\mathrm{S}_{1} \mathrm{~S}^{1}, 6$ is for $\mathrm{P}_{1} \mathrm{P}_{2}, 7$ is for $\mathrm{P}_{1} \mathrm{~S}_{2}, 8$ is for $\mathrm{S}_{1} \mathrm{~S}_{2}, 9$ is for $\mathrm{P}_{1} \mathrm{~S}_{2} \mathrm{P}^{2}, 10$ is for $\mathrm{P}_{1} \mathrm{P}_{2} \mathrm{~S}_{3}, 11$ is for $\mathrm{P}_{1} \mathrm{P}_{2} \mathrm{P}_{3}, 12$ is for $\mathrm{S}_{1} \mathrm{~S}_{2} \mathrm{~S}^{2}, 13$ is for $\mathrm{P}_{1} \mathrm{P}_{2} \mathrm{~S}^{2}$, and 14 is for $\mathrm{P}_{1} \mathrm{~S}_{2} \mathrm{P}^{2} \mathrm{P}^{1}$

seismic phases, which can be further confidentially supported by the ray-tracing algorithm, such as we did by the multistage MSPM method.

\section{Conclusions}

To obtain pure P- or S-wavefields, we examine and compare two kinds of separate elastic wave equations (that is the first-order separate velocity-stress equations and the second-order separate displacement-stress equations) for seismic wavefield simulation. The comparisons of wavefield snapshots, common-source gathers, and individual seismograms are given. Furthermore, the stacked seismic wavefields for both the pure P- and $\mathrm{S}$-wavefields are compared with the mixed wavefields obtained by the first-order and second-order full elastic wave equations. The simulation results for the three different models indicate that (1) comparable pure P- 

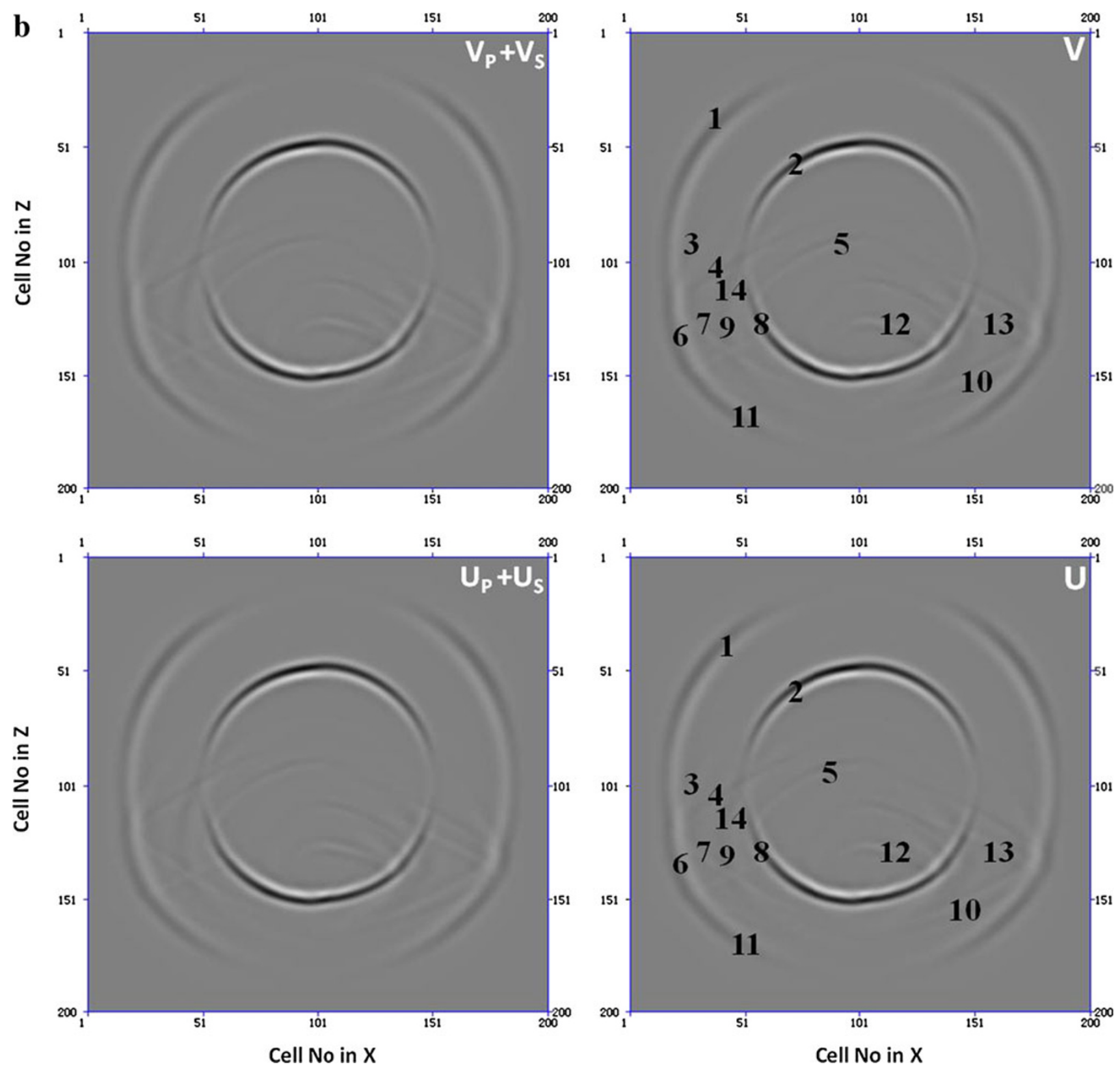

Fig. 5 continued

and S-wavefields can be obtained by solving the firstorder and second-order separate elastic equations; (2) the stacked wavefields for both the pure $\mathrm{P}$ - and S-wavefields are similar to those mixed wavefields obtained by the corresponding (first-order or secondorder) full elastic wave equations; (3) the computational accuracies are at a similar levels for the four different approaches, but the separate elastic wave equations consume more CPU time, nearly one and a half times as much as full elastic wave equations; (4) the separate elastic wave equation simulation has the advantage over the full elastic wave equation simulation in terms of phase identification and onset time picking; and (5) it is easy to fully separate the seismic wavefield directly by using the first-order or second-order separate elastic wave equations. 


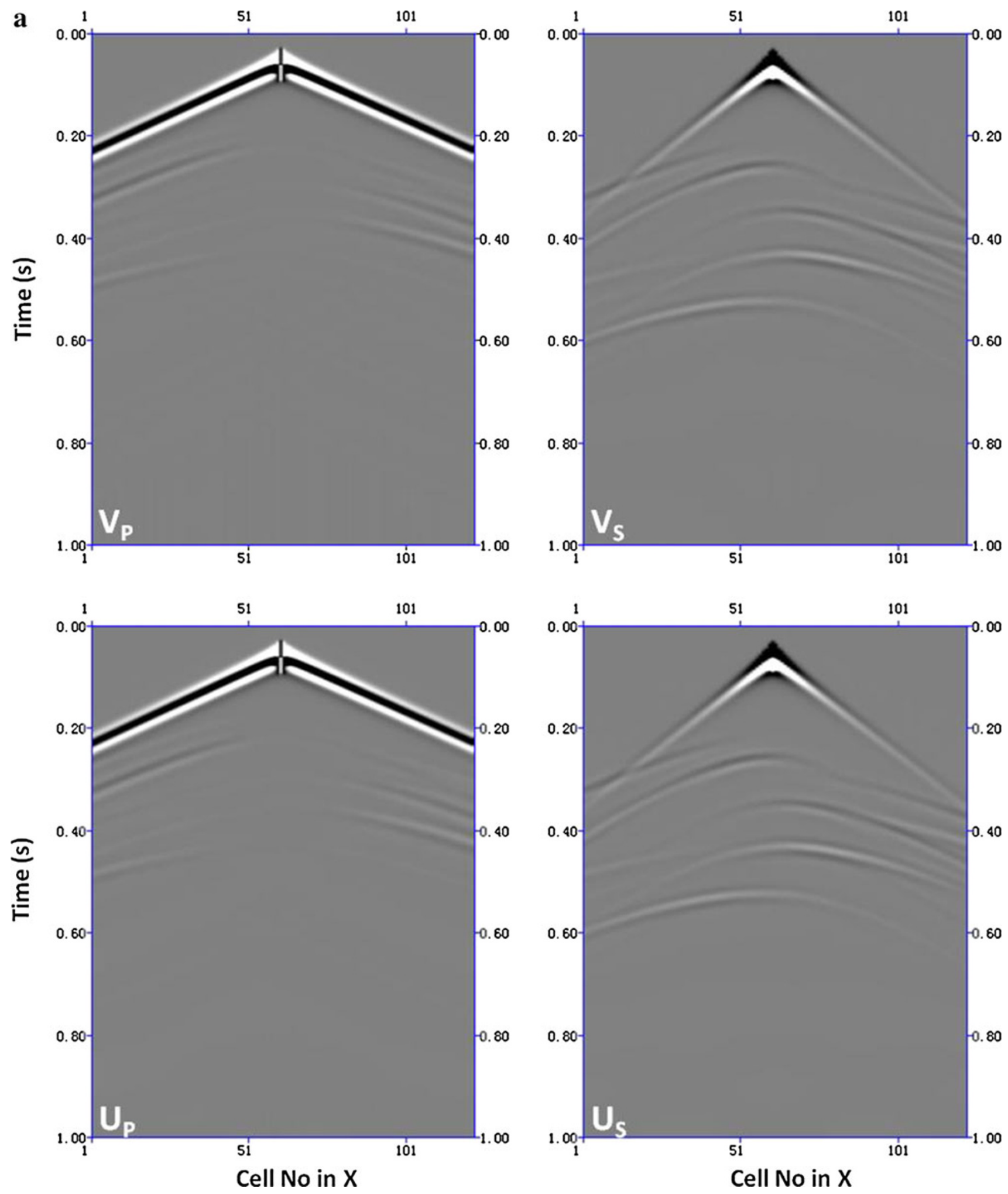

Fig. 6 a Similar to Fig. 2a, but for a three-layered fault model at location of $z=990 \mathrm{~m}$ obtained by the two different separate elastic wave equation approaches. b Similar to (a), but obtained by the two different separate elastic wave equation approaches and plus the stacked results of $V_{\mathrm{P}}+V_{\mathrm{S}}$ and $U_{\mathrm{P}}+U_{\mathrm{S}}$. In the figure, the numbers from 1 to 10 indicate different seismic phases. 1 for $\mathrm{P}, 2$ for $\mathrm{S}, 3$ for $\mathrm{P}_{1} \mathrm{P}^{1}, 4$ for $\mathrm{P}_{1} \mathrm{~S}^{1} / \mathrm{S}_{1} \mathrm{P}^{1}, 5$ for $\mathrm{S}_{1} \mathrm{~S}^{1}, 6$ for $\mathrm{P}_{1} \mathrm{P}_{2} \mathrm{P}^{2} \mathrm{P}^{1}, 7$ for $\mathrm{S}_{1} \mathrm{P}_{2} \mathrm{P}^{2} \mathrm{P}^{1} / \mathrm{P}_{1} \mathrm{P}_{2} \mathrm{P}^{2} \mathrm{~S}^{1}, 8$ for $\mathrm{S}_{1} \mathrm{P}_{2} \mathrm{~S}^{2} \mathrm{P}^{1} / \mathrm{P}_{1} \mathrm{~S}_{2} \mathrm{P}^{2} \mathrm{~S}^{1}, 9$ for $\mathrm{S}_{1} \mathrm{~S}_{2} \mathrm{~S}^{2} \mathrm{P}^{1} / \mathrm{P}_{1} \mathrm{~S}_{2} \mathrm{~S}^{2} \mathrm{~S}^{1}, 10$ for $\mathrm{S}_{1} \mathrm{~S}_{2} \mathrm{~S}^{2} \mathrm{~S}^{1}$ 

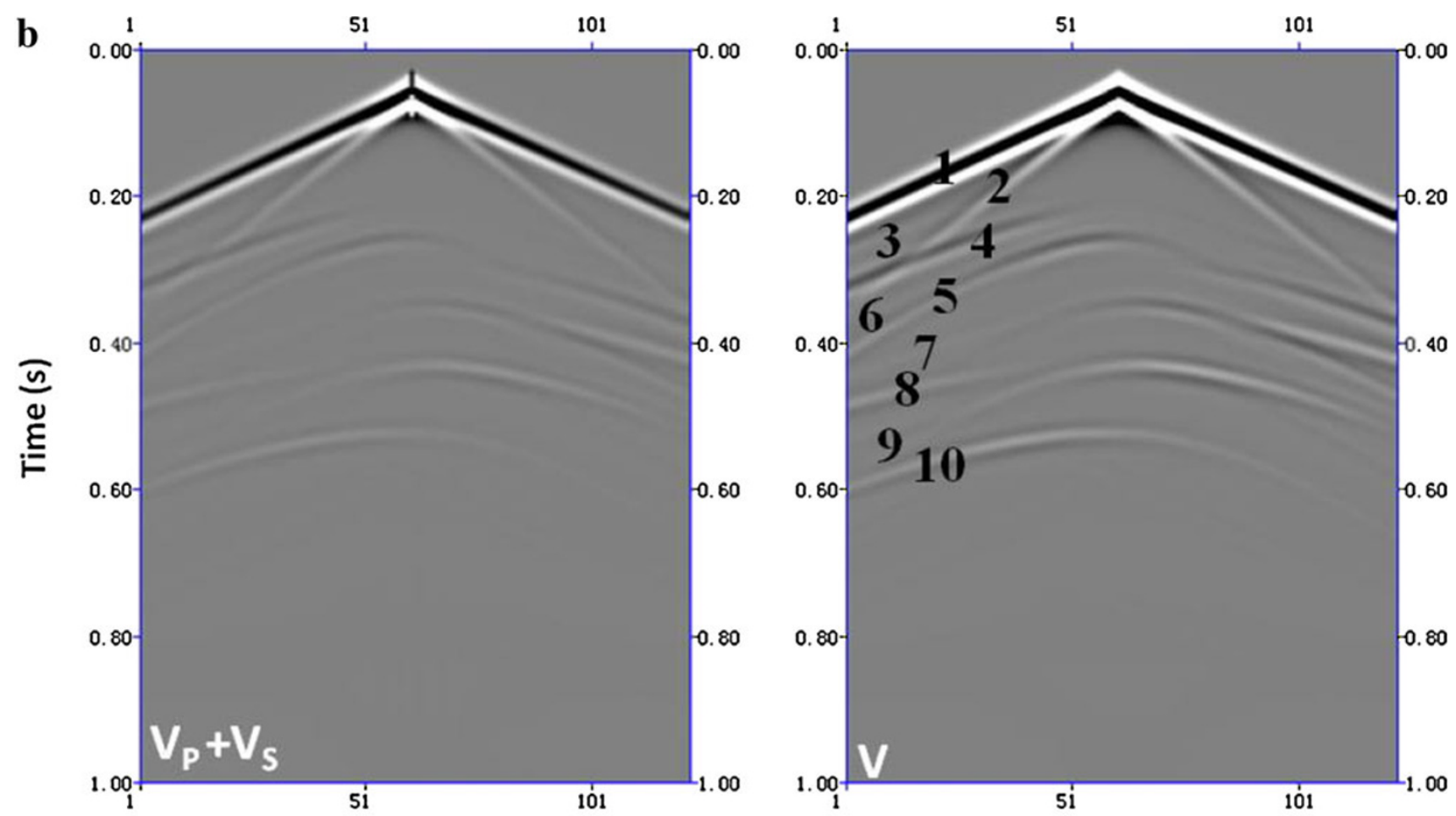

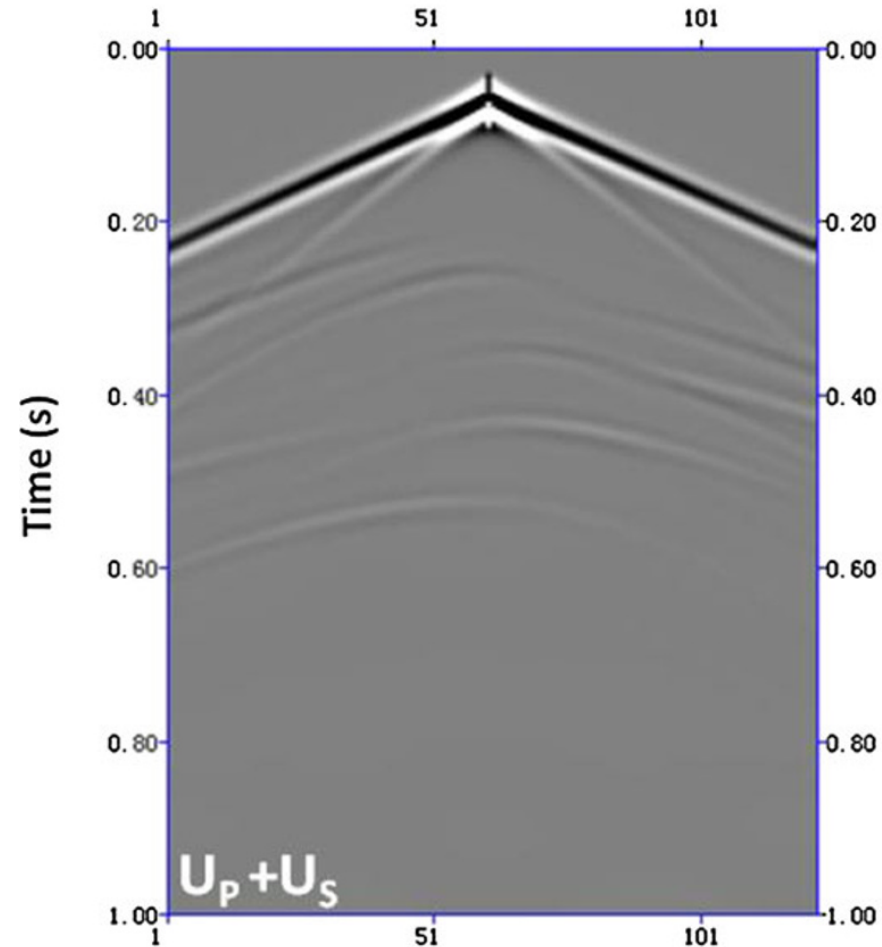

Cell No in X
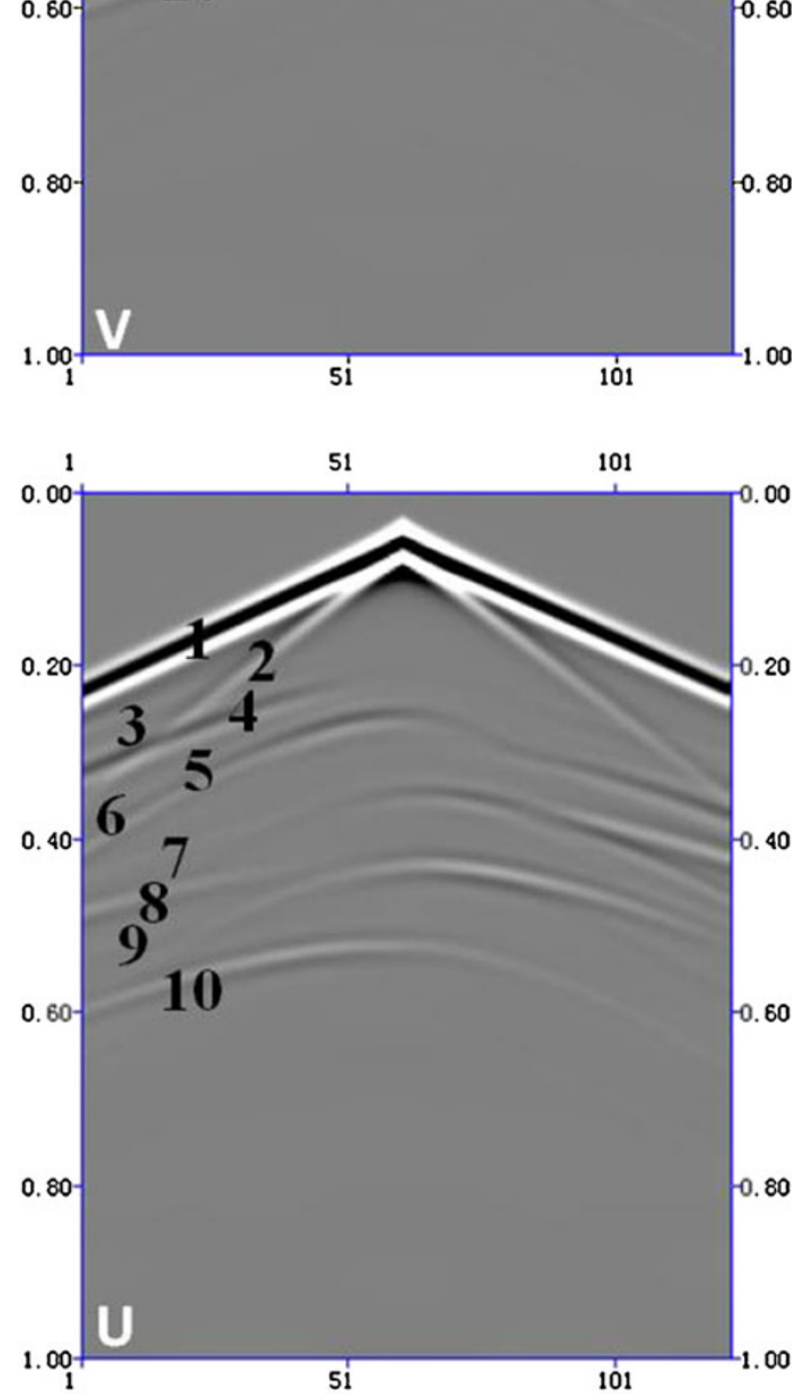

Cell No in X

Fig. 6 continued 
a

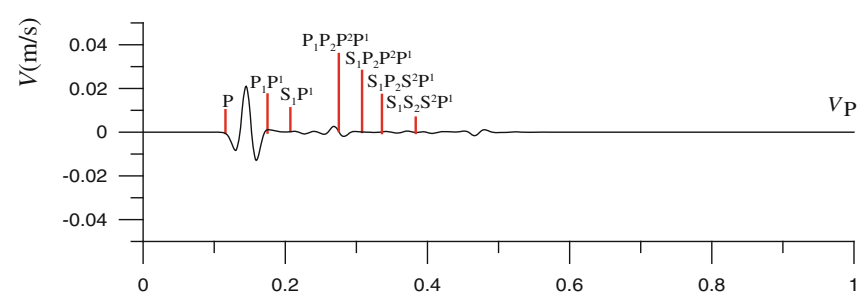

$$
\widehat{\Xi}
$$
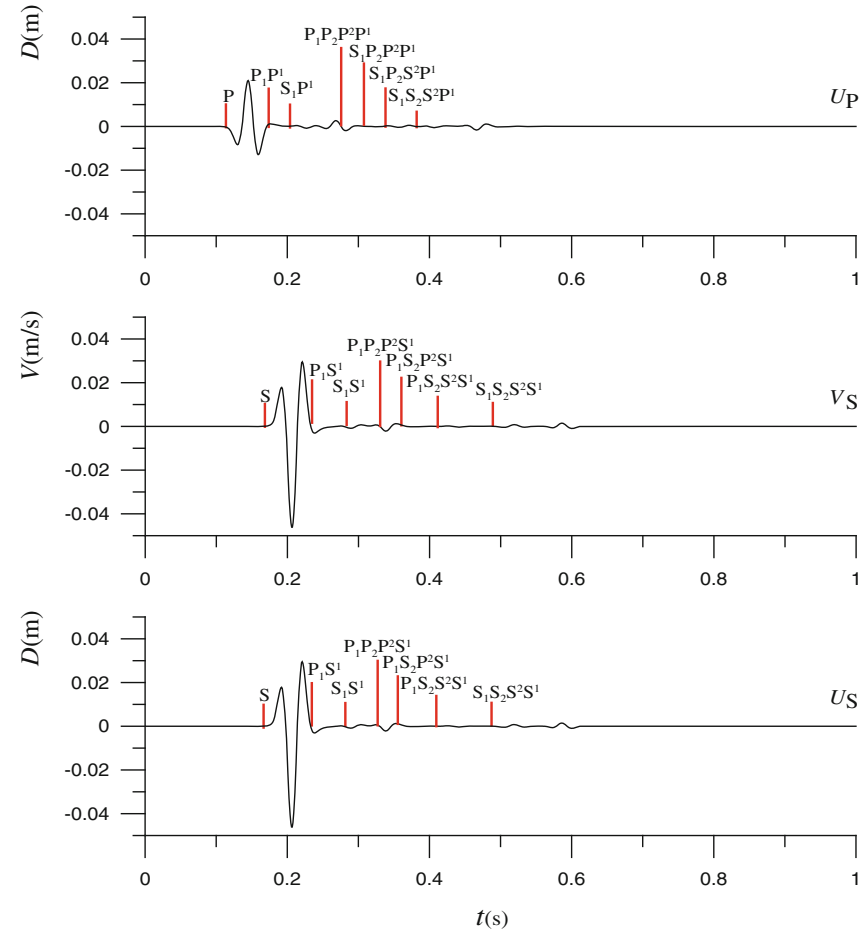

b
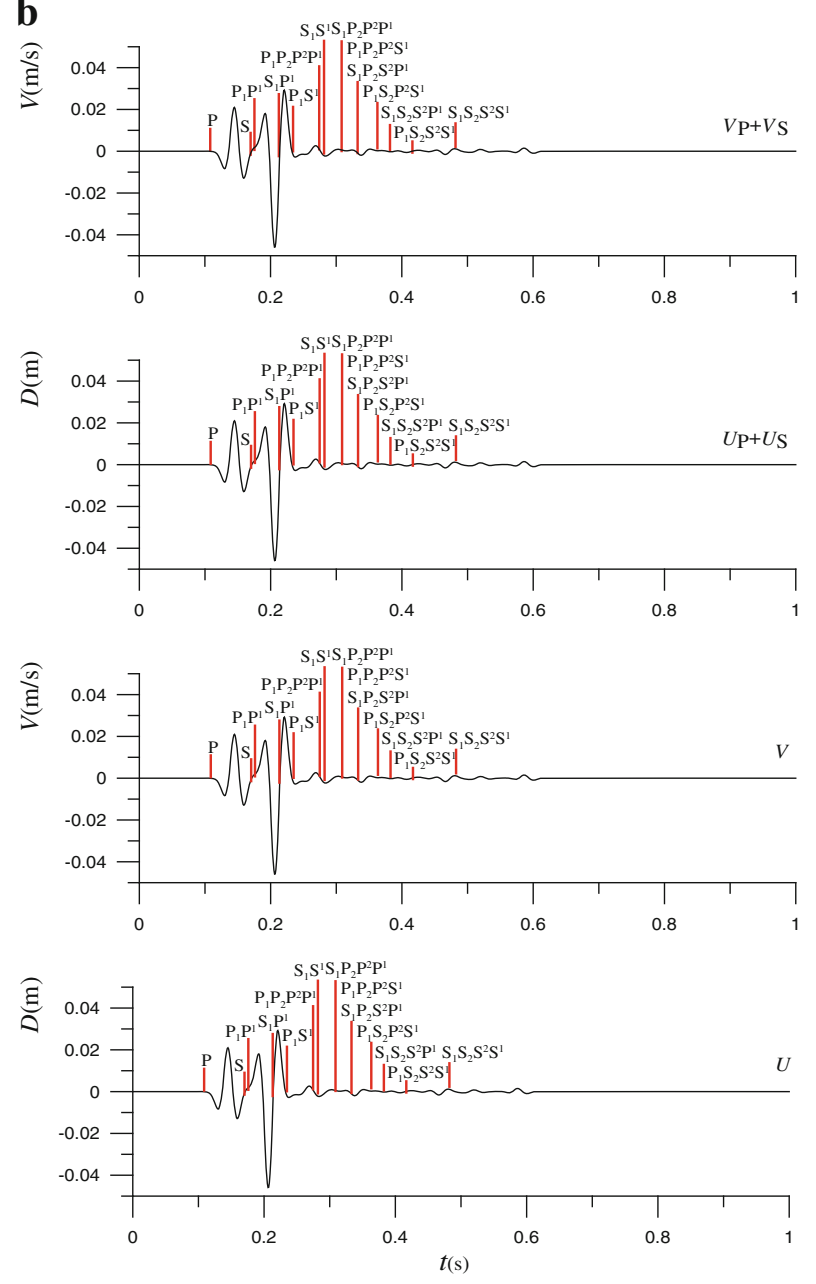

Fig. 7 a Similar to Fig. 3a, but for a three-layered fault model at location $(x=690 \mathrm{~m}, z=890 \mathrm{~m})$ of $z$-component synthetic seismogram obtained by the two different separate elastic wave equation approaches. b Similar to (a), but obtained by the two different full elastic wave equation approaches and plus the stacked results of $V_{\mathrm{P}}+V_{\mathrm{S}}$ and $U_{\mathrm{P}}+U_{\mathrm{S}}$

Acknowledgments This research work was partially supported by China National Major Science and Technology Project (Subproject No: 2011ZX05024-001-03).

\section{References}

Alterman Z, Karal F (1968) Propagation of seismic wave in layered media by finite difference methods. Bull Seismol Soc Am 58:367-398

Bai C-Y, Tang XP, Zhao R (2009) 2D/3D multiply transmitted, converted and reflected arrivals in complex layered media with the modified shortest path method. Geophys J Int 179:201-214

Cerjan C, Kosloff D, Kosloff R, Reshef M (1985) A nonreflecting boundary condition for discrete acoustic and elastic wave equations. Geophysics 50:705-708

Cho WH (1991) Decomposition of vector wavefield data. PhD Thesis, Texas A\&M University

Donati MS, Stewart RR (1996) P- and S-wave separation at a liquidsolid interface. J Seism Explor 5:113-127

Dong LG, Ma ZT, Cao JZ, Wang HZ, Geng JH, Lei B, Xu SY (2000) A staggered-grid high-order difference method of one-order elastic wave equation. Chin J Geophys 43(3):411-419 (in Chinese with English abstract)

Fang X, Fehler M, Zhu Z, Zheng Y, Burns D (2012) Reservoir fracture characterizations from seismic scattered waves. SEG technical program expanded abstracts 2012

Fang X, Fehler M, Chen T, Burns D, Zhu Z (2013) Sensitivity analysis of fracture scattering. Geophysics 78(1):T1T10

Greenhalgh SA, Mason IM, Mosher CC, Lucas E (1990) Seismic wavefield separation by multi-component tau-p filtering. Tectonophysics 173:53-61

Hendrick N, Hearn S (2003) Introduction to vector-processing techniques for multi-component seismic exploration. In: 16th geophysical conference and exhibition, ASEG, extended abstracts CDROM, Brisbane

Leaney WS (1990) Parametric wavefield decomposition and applications. In: 60th Annual international meeting, SEG, expanded abstracts, pp 26-29

Li ZC, Zhang H, And Liu QM (2007) Elastic wave staggered grids high-order finite difference method for wave field separation numerical simulation. Oil Geophys Explor 42(5):510-515 (in Chinese with English Abstract) 
Ma DT, Zhu GM (2003) The elastic wave field P-wave and the S-wave decompose numerical simulation. Oil Geophys Explor 38(5):482-486 (in Chinese with English Abstract)

Shang X, de Hoop MV, van der Hilst RD (2012) Beyond receiver functions: passive source reverse time migration and inverse scattering of converted waves. Geophys Res Lett 39(15):L16310

Sun R, Chow J, Chen K-J (2001) Phase correction in separation Pand S-waves in elastic data. Geophysics 66:1515-1518

Sun R, McMechan GA, Hsiao HH, Chow J (2004) Separating P- and $\mathrm{S}$-waves in prestack $3 \mathrm{D}$ elastic seismograms using divergence and curl. Geophysics 69:286-297
Tang XP, Bai CY, Liu KH (2012) Elastic wavefield simulation using separated equations through pseudo-spectral method. Oil Geophys Explor 47(1):19-26 (in Chinese with English Abstract)

Virieux J (1986) P-SV wave propagation in heterogeneous media: velocity-stress finite-difference method. Geophysics 51:889-901

Yan R, Xie X (2012) An angle-domain imaging condition for elastic reverse time migration and its application to angle gather extraction. Geophysics 77:S105-S115 